\title{
Neurological involvement in type 1 (adult) Gaucher's disease
}

\author{
RO McKERAN, P BRADBURY, D TAYLOR, G STERN \\ From Atkinson Morley's University College and Maida Vale Hospitals for Nervous Diseases, London, UK
}

SUMMARY A case of type 1 (adult) Gaucher's disease with a late onset tapeto-retinal degeneration and an initially dopamine responsive extrapyramidal syndrome is described. The literature reporting neurological involvement in type 1 Gaucher's disease is reviewed, and it is concluded that the absence of symptoms and signs of nervous system involvement cannot be used as the sole basis for the classification of this type of Gaucher's disease.

Prior to the report by Miller, McCluer and Kanfer in $1973^{1}$ there had been no convincing evidence of neurological involvement in the type 1 (adult) form of Gaucher's disease. However Brady ${ }^{2}$ considered their two cases as examples of type 3 (juvenile) Gaucher's disease solely on the basis that the central nervous system was involved, despite the delayed onset of neurological involvement (29 and 36 years of age), and levels of glucocerebrosidase activity within the range found in patients with uncomplicated type 1 (adult) Gaucher's disease. The present case report extends the spectrum of neurological involvement in the type 1 (adult) form to include a late onset progressive tapeto-retinal degeneration and a dopamine responsive extrapyramidal syndrome. It is not possible at present to predict which patients will have late onset nervous system involvement in type 1 (adult) Gaucher's disease on the basis of residual glucocerebrosidase activity. Thus the clinical phenotype remains the basis for classification of this disease and it seems illogical to include type 1 patients with late onset neurological involvement in the juvenile category (type 3 ) thus ignoring all the other clinical differences between these groups of patients. It may have the added disadvantage of grouping together different enzyme variants.

Address for reprint requests: Dr RO McKeran, Atkinson Morley's Hospital, 31 Copse Hill, Wimbledon, SW20 0NE, UK.

Received 16 May 1983 and in revised form 10 July 1984.

Accepted 14 July 1984

\section{Case report}

Our patient, an Ashkenazic Jewess, was born in 1930 non-consanguinous parents. At 3 weeks of age she 윽 developed a severe furunculosis which resolved withog specific treatment. She had three pyrexial episodes lasting 2 to 3 days over a period of 6 months at the age of 2 years, $\frac{D}{O}$ during each of which she was apathetic and listless withogt any obvious source of infection. Her spleen was firs noticed to be enlarged at the age of 2 and her liver at years. From the age of 5 she had suffered repeated attack $\overrightarrow{0}$ of pain and stiffness in her knees with elevated tempera- or ture sometimes coming on 1 week after minimal trauma, and between the ages of 15 and 23 recurrent attacks of bony central chest pain lasting up to 1 week. The diagnosis of Gaucher's disease was made at the age of 17 from the clinical history, the presence of hepatosplenomegaly, typi- 응 cal changes on radiographs of the long bones and the presence of Gaucher cells in a sternal marrow biopsy. An iron deficiency anaemia (haemoglobin of $9 \mathrm{~g} / \mathrm{al}$ ) was treated with long term iron tablets. A depressive illness at the age of 30 required psychiatric support and medication. She was admitted to hospital when 30 with a 12 month history of increasing breathlessness and fatiguability, and by then her abdominal swelling had become an embarrassment and was uncomfortable. Her liver was enlarged to 4 inches beyond the right costal margin with a smooth non tender edge, and the spleen had enlarged to beyond the umbilicus with a smooth non tender edge and notch. She had pale conjunctivae and marked pigmentation of the legs below the knees. Her anaemia haemoglobin $9 \mathrm{~g} / \mathrm{al}$ ) and prolonged prothrombin time (ratio of $57 \%$ ) were treated with iron tablets, injections and Vitamin $K$, and she was transfused three pints of fresh blood at splenectomy.

At age $40 \mathrm{yr}$ she had a vaginal sterilisation without com- $\mathrm{N}$ plication having had 2 full term normal pregnancies. She $N$ 
was readmitted at 44 with severe sacral and pelvic bony pain which required strong analgesics and took 8 days to resolve. She continued to be mildly anaemic (haemoglobin $11.7 \mathrm{~g} / \mathrm{al}$ ) with a white count of $13,000^{-3}$, a normal number of platelets and an ESR of $63 \mathrm{~mm}$ in 1 hour. Liver function tests, plasma proteins, calcium, phosphate, alkaline phosphatase, and blood sugar were normal. Her acid phosphatase was elevated to $11.4 \mathrm{KAU}$ (1-3.5 normal range). She was reinvestigated at the age of 46 with a view to enzyme replacement with liposomes. Her acid phosphatase was $12 \cdot 2 \mathrm{KAU}$, radiographs of her long bones were characteristic of Gaucher's disease, as was a liver biopsy, and her white cell glucocerebrosidase activity was reduced to $2.8 \mathrm{nmols}$ per $\mathrm{mg}$ of protein per hour (normal range 7.4-32 nmols per $\mathrm{mg}$ of protein per hour, and for type 1 Gaucher's $0.78-3.9$ nmols per $\mathrm{mg}$ of protein per

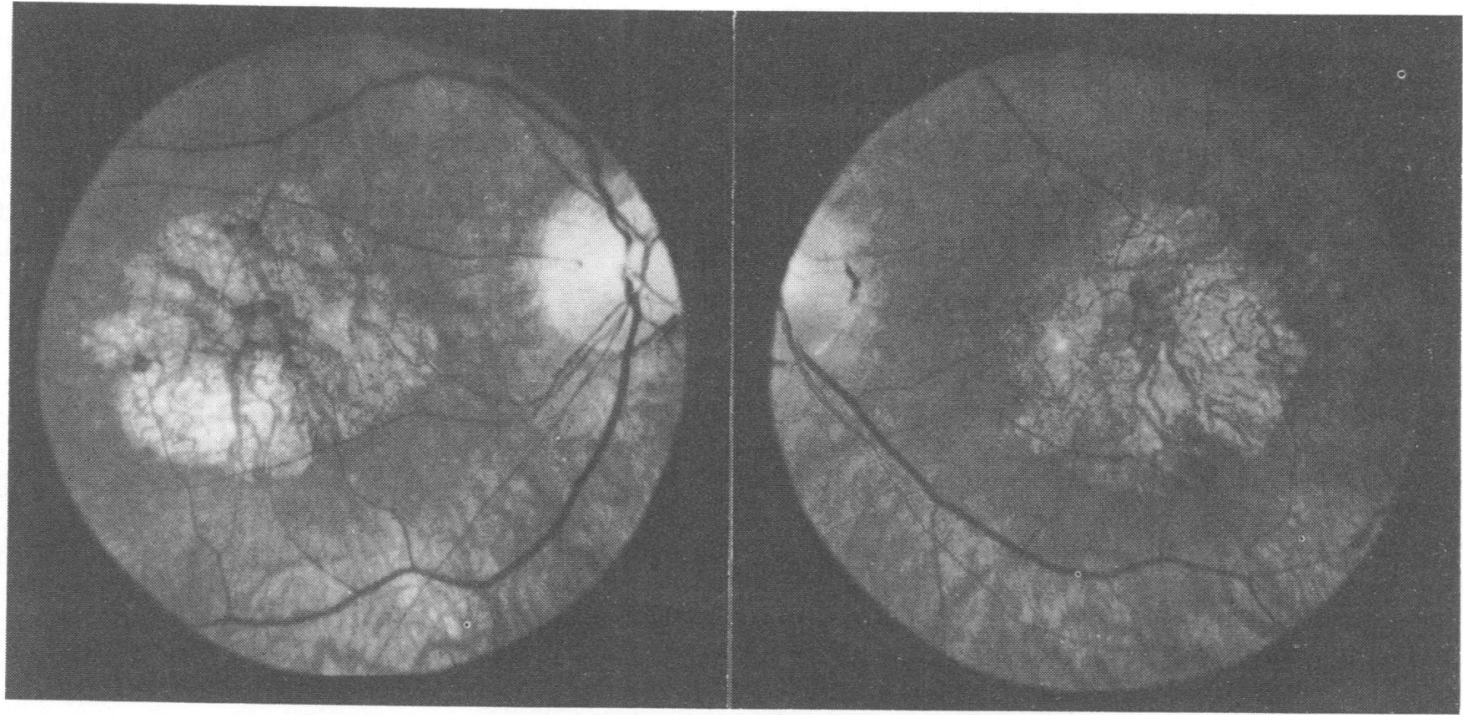

Fig 1 The fundi when aged 48 yr show marked retinal arteriolar attenuation, optic atrophy, and a well defined pigment epithelial defect with some central pigment clumping. The visual acuity was 1/60 in both eyes.

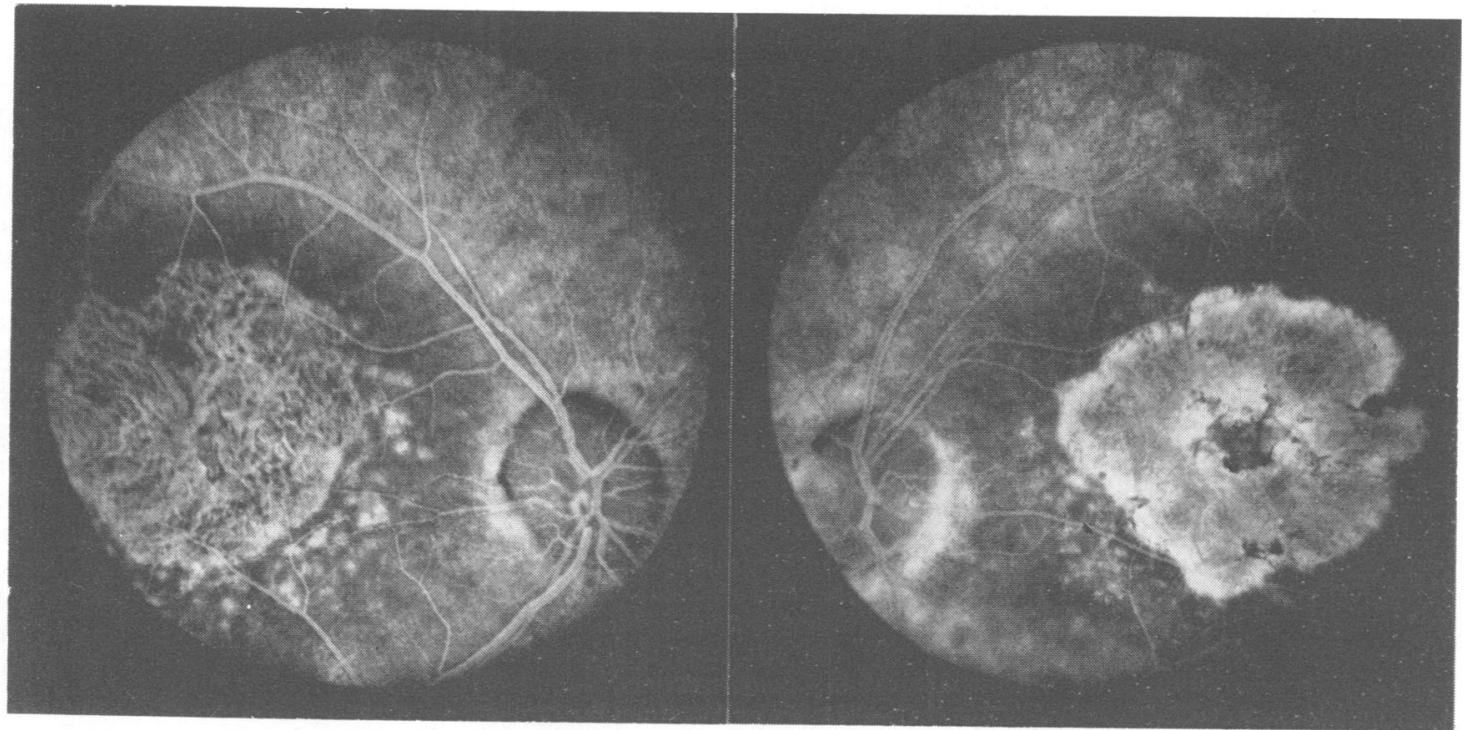

Fig 2 A fuorescein angiogram delineates the retinal epithelial defects and shows preservation of the middle sized choroidal vessels in the left eye, shown on the right. The diffuse fuorescence in the right macula is from choroidal vessels at a later stage in the fuorescein study than the picture on the right. 
hour). She received two intravenous infusions of glucocerebrosidase entrapped within liposomes (160 and 150 units; 1 unit of activity hydrolysed $0.7 \mathrm{mgms}$ of substrate per minute at $37^{\circ} \mathrm{C}$ ), without significant side effect or noticeable benefit.

Her vision began to deteriorate at the age of $37 \mathrm{yr}$ affecting first the left and then the right eye. She noticed that parts of her central visual field were missing. Reading became difficult at 39 , she started to use a hand lens at 42 and she read her last book at 45 . At 48 she could not read or write and her visual field she likened to a jigsaw puzzle which had not been put together properly. On formal examination her best visual acuity at 39 was $6 / 9$ right eye, $6 / 12$ left eye, at 44 it had fallen to $6 / 12$ right eye, $6 / 18$ left eye; and at 48 was less than 1/60 bilaterally. She had been, like her mother, night blind all her life. Her visual fields were generally constricted with absolute central scotomata, the optic discs were pale, there was marked attenuation of the retinal vessels with loss of the nerve fibre layer and of the macular pigment epithelium and overlying retina. (figs 1,2). An electro-retinogram using a gold foil conjunctival electrode and skin electrodes, demonstrated that both averaged responses and single flash responses were absent.

She had first become aware of a painless stiffness in the left knee whilst sitting in a car at 45 , and this was very soon noticed in the right knee. Although initially localised to the knees and intermittent, within 12 months it had become continuous and generalised. Her face became expressionless, chewing difficult, her speech slurred, she developed a tendency to dribble saliva, with a shuffling gait and stooped posture with difficulty in turning in bed. She has become aware of a generalised state of muscle tension at 45 which initially intermittent had become continuous by 46 . On examination at 48 , she had an immobile facies, rigidity in all 4 limbs with cogwheel rigidity at the wrists, a stooped posture and bradykinesia. She was started on Sinemet 275 mgms building up to three times a day and within a week her symptoms and signs had completely resolved. After an initial good response to Sinemet (levodopa $250 \mathrm{mg}$, carbidopa $25 \mathrm{mg}$ ) within 2 years she had developed severe Parkinsonian features and had become almost immobile and chair bound. Attempts to manipulate her Sinemet dose to therapeutic advantage led to distressing dyskinesia and occasional psychotic episodes.

\section{Discussion}

Gaucher's disease is the most common inherited metabolic disorder of glycolipid metabolism, and is due to reduced activity of the enzyme glucocerebrosidase which catalyses the hydrolytic cleavage of glucose from glucocerebroside. It has been divided into three clinical groups all of which are inherited in an autosomal recessive manner. The adult chronic non-neuronopathic form (type 1) may present clinically at any time from birth to old age. All three groups have hepatosplenomegaly, hypersplenism, Gaucher cells in the bone marrow and reduced levels of the enzyme glucocerebrosidase in their organs and tissues. The absence of symptoms and signs of central nervous system involvement has been used as the basis for the classification of type $1 \frac{\mathrm{O}}{Z}$ (adult) Gaucher's disease, together with levels of $\mathbb{\Phi}$ residual glucocerebrosidase activity in the range of 12-45 per cent of normal. ${ }^{2}$ Only patients belonging to the type 1 category have been thought to live beyond the third decade of life. ${ }^{2}$ The infantile or $D$ acute neuronopathic form of Gaucher's disease (type 2) presents before the age of 6 months and is $\underset{\overline{2}}{5}$. usually fatal by the age of 2 years. It is characterised $\stackrel{0}{\vec{*}}$ by a protuberant abdomen, hepatosplenomegaly $:$ and the onset of neurological involvement usually $\overrightarrow{\overrightarrow{\vec{D}}}$ around six months of age and, rarely, shortly after birth. There is a regression of psychomotor development with spasticity. Most commonly $\frac{0}{\bar{c}}$ encountered are strabismus, hypertonicity, and retroflexion of the head. Nuchal rigidity, trismus, $\propto$ ocular palsy, dysphagia, laryngeal stridor, $\infty$ hyperreflexia, extensor plantar responses, seizures, $\vec{O}$ sensory loss and mental retardation are less fre- $\overrightarrow{\vec{H}}$ quently encountered. ${ }^{2}$ The average survival is $9 \vec{\omega}$ months. The neurological involvement in the juvenile variety (type 3 ) of Gaucher's disease is characterised by the onset in the first or second decade of life of mental retardation or deterioration, seizures, behaviour disorders, clumsy and stiff $\stackrel{\sim}{-}$ movements, tremor, defective co-ordination, distu $\vec{\nabla}$ bances of extraocular movements (usually impairêt 을 conjugate lateral gaze) hypertonicity and abnorm encephalograms. ${ }^{2}$

There is increasing evidence that neurologicâj involvement can occur as a late complication of type 1 (adult) Gaucher's disease. Miller, McCluer an Kanfer ${ }^{1}$ described two cases characterised by onse $\overrightarrow{\vec{\theta}}$ at the age of 29 and 36 of a progressive tendency to ${ }_{0}^{\circ}$ convulsions, mental deterioration, a disturbance of extraocular movements and an abnormal encephalogram.

The 39-year-old patient reported by $\mathrm{King}^{3}$ had developed a progressive tendency to myoclonic epilepsy and mental deterioration from the age of $\stackrel{\square}{\perp}$ 17. An acute confusional state leading to coma in a $\overrightarrow{\overrightarrow{0}}$ 46-year-old woman with type 1 (adult) Gaucher's $\frac{3}{3}$ disease was shown at necropsy to be associated with $\bar{P}$ evidence of fat embolism possibly derived from bone marrow infiltrated with Gaucher cells ${ }^{4}$ leading to diffuse intravascular coagulation. Other authors have suggested an association with the development $\frac{0}{0}$ of a peripheral cryoglobulinaemic neuropathys and a 3 familial psychosis. ${ }^{6}$ There are earlier reports in the literature of patients with a clinical diagnosis of Gaucher's disease before the availability of specific 0 enzyme assays who have developed neurological involvement after the first decade of life. ${ }^{78}$ In the $\frac{D}{0}$ case described by Davidson, ${ }^{8}$ a 26 -year-old Polish Jew with adult Gaucher's disease and facial immo- N bility, swelling and loss of cells in the putamen and 
caudate nuclei, slight swelling of Purkinge cells and large foam cells in the spinal cord were found at necropsy. Diezel ${ }^{9}$ described perivascular Gaucher cells and ganglion cell changes in the cortex and cerebellum of a 61-year-old man with apparent adult Gaucher's disease. Gaucher cells have been described in the pituitary and hypothalamus ${ }^{1011}$ spinal cord ${ }^{8}$ and meninges. ${ }^{12}$ Recently ${ }^{13}$ a 51-year-old man with adult onset Gaucher's disease dying with renal failure without neurological involvement until the terminal event was examined at necropsy and found to have Gaucher cells throughout the brain and leptomeninges confined to the perivascular spaces of small blood vessels. Quite commonly associated was an intense perivascular gliamesadermal fibrillary reaction. No neuronal storage material was seen.

The ocular abnormalities associated with type 1 (adult) Gaucher's disease have included cuneiform, triangular thickening of the bulbar conjuntiva on the nasal and temporal sides of the corneoscleral limbus, ${ }^{2}$ retinal haemorrhages and oedema, ${ }^{4}$ a macular red spot $^{14}$ and perimacular degeneration. ${ }^{15-17}$

The patient described in this communication had been diagnosed as a case of type 1 (adult) Gaucher's disease on the basis of histology of the bone marrow, spleen and liver, characteristic radiological changes, a raised serum acid phosphatase (uninhibited by 1-tartrate) and a reduced level of white cell glucocerebrosidase activity within the range of type 1 (adult) Gaucher's disease. Until the age of 38 her clinical course had been entirely in keeping with that diagnosis. Although minimal cystic changes at the macula have been previously described in type 1 Gaucher's disease, the extent of involvement in the present case is remarkable. Our patient had an extrapyramidal syndrome characterised by an initially dopamine responsive bradykinesia and rigidity without tremor. It is possible that idiopathic nigrostriatal degeneration has occurred coincidentally in this patient and that the combination of hereditory night blindness or some other disease and adult type 1 Gaucher's has given rise to her tapeto-retinal degeneration. However, it is perhaps equally likely that an extrapyramidal syndrome and progressive tapeto-retinal degeneration is a true late onset manifestation of type' 1 Gaucher's disease. In juvenile Gaucher's disease, for example, extrapyramidal features are frequently encountered, ${ }^{2}$ and in the cases described by Neil, Glew and Peters ${ }^{6}$ extrapyramidal features were described in two of their three cases who also had a psychosis. The biochemical factors that determine the later development of neurological involvement in type 1 (adult) Gaucher's disease require to be clarified. The present case had an early onset and low levels of enzyme activity both of which could conceivably be relevant in that respect.
We thank Professor O Wrong for his permission to publish the details of this case, Dr E Young of the Institute of Child Health for performing the beta glucocerebrosidase activity on this patient's white cells, and Dr Andrew Gale of University College Hospital.

\section{References}

' Miller JD, McCluer R, Kanfer JN. Gaucher's disease: Neurologic disorder in adult siblings. Ann Intern Med 1973;78:883-7.

${ }^{2}$ Brady RO. Glucosyl ceramide lipidosis: Gaucher's disease. In: Stanbury JB, Wyngaarden JB, Frederickson DS, eds. The Metabolic Basis of Inherited Disease. New York, McGraw-Hill 1978:731-46.

${ }^{3}$ King JO. Progressive myoclonic epilepsy due to Gaucher's disease in an adult. $J$ Neuro Neurosurg Psychiatry 1975;38:849-54.

${ }^{4}$ Melamed E, Cohen C, Soffer D, Lavy S. Central nervous system complication in a patient with chronic Gaucher's disease. Eur Neurol 1975; 13:167-75.

s Benjamin D, Dover D, Pick AI, Zer M, Dintsman M, Pinkhas J. Peripheral cryoglobulinaemic neuropathy in a patient with Gaucher's disease. Acta Haematol, Basal 1978;60:117-21.

- Neil JF, Glew RH, Peters SP. Familial psychosis and diverse neurological abnormalities in adult-onset Gaucher's disease. Arch Neurol 1979;36:95-99.

7 Van Bogaert L, Fröhlich A. Un cas de maladie de Gaucher de l'adulte avec syndrome de Raynaud pigmentation et rigidite du type extrapyramidal aux membres infericurs. Ann Med (Paris) 1939;45:57-70.

${ }^{8}$ Davidson C. Disturbances in lipid metabolism and the central nervous system. Mt Sinai J Med 1942;9:389406.

${ }^{9}$ Diezel PB. Histochemische Untersuchungen an den Globoidzellen der familiaren infantilen diffusen sklerose vom typus Krabbe. Virch Archiv 1955;327:20628.

10 Teilum G. Die Gauchersche Krankheit. Acta Med Scand 1944;116: 170-90.

${ }^{11}$ Morrison AN, Lane M. Gaucher's disease with ascites: a case report with autopsy findings. Ann Intern Med 1955;42:1321-9.

12 Chango-lo M Yam LT, Rubenstone AI. Gaucher's disease. Review of literature and report of 12 new cases. Am J Med Sci 1967;254:303-15.

${ }^{13}$ Soffer D, Yamanaka T, Wenger DA, Suziki K. Central nervous system involvement in adult Gaucher's disease. Acta Neuropathol (Berl) 1980;49:1-6.

14 Walsh FB, Hoyt AB. Clinical Neuro-ophthalmology. Baltimore, Williams and Wilkins 1969:829.

is Petrohelos M, Tricoulis D, Kotsiras I et al. Ocular manifestation of Gaucher's disease. Am J Ophthalmol 1975;80: 1006-10.

${ }^{16}$ Collier M. Degenerescence maculaire d'un type special dans un cas d maladie de Gaucher. Bull Sec Ophthalmol Fr 1961;6:497.

${ }^{17}$ Eyb C. Augenhintergrundveränderungen bei der kindlichen gaucherschen Erkrankung Wien. Klin Wochenschr 1952;64:38-39. 